\title{
Locus Heterogeneity of Autosomal Dominant Long QT Syndrome
}

\author{
Mark Curran, *\$ Donald Atkinson, *\$s Katherine Timothy," G. Michael Vincent, *\| \\ Arthur J. Moss, ** Mark Leppert, ${ }^{* 1}$ and Mark Keating *\$\$ \\ ${ }^{*}$ Division of Cardiology, ${ }^{\ddagger}$ Department of Human Genetics, ${ }^{\S}$ Eccles Program in Human Molecular Biology and Genetics, \\ 'Howard Hughes Medical Institute, University of Utah Health Sciences Center, Salt Lake City, Utah 84112; \\ "Department of Medicine, LDS Hospital, Salt Lake City, Utah 84143; and ** Department of Medicine, \\ University of Rochester Medical Center, Rochester, New York 14642
}

\begin{abstract}
Autosomal dominant long QT syndrome (LQT) is an inherited disorder that causes syncope and sudden death from cardiac arrhythmias. In genetic linkage studies of seven unrelated families we mapped a gene for LQT to the short arm of chromosome 11 (11 p15.5), near the Harvey ras-1 gene (H ras-1). To determine if the same locus was responsible for LQT in additional families, we performed linkage studies with DNA markers from this region ( $\mathrm{H}$ ras-1 and MUC2). Pairwise linkage analyses resulted in logarithm of odds scores of -2.64 and -5.54 for kindreds 1977 and 1756, respectively. To exclude the possibility that rare recombination events might account for these results, we performed multipoint linkage analyses using additional markers from chromosome 11 p15.5 (tyrosine hydroxylase and D11S860). Multipoint analyses excluded $\sim 25.5$ centiMorgans of chromosome 11 p15.5 in K1756 and $\sim 13$ centiMorgans in K1977. These data demonstrate that the LQT gene in these kindreds is not linked to $H$ ras-1 and suggest that mutations in at least two genes can cause LQT. While the identification of locus heterogeneity of LQT will complicate genetic diagnosis, characterization of additional LQT loci will enhance our understanding of this disorder. (J. Clin. Invest. 1993. 92:799-803.) Key words: genetic linkage $\bullet$ cardiac arrhythmias - sudden death • Romano-Ward syndrome • QT prolongation
\end{abstract}

\section{Introduction}

In the long QT syndromes (LQT), ${ }^{1}$ individuals suffer from syncope and sudden death due to cardiac arrhythmias, specifcally torsade de pointes and ventricular fibrillation. Many of these individuals also have prolongation of the QT interval and other repolarization abnormalities on electrocardiograms. LQT can be broadly classified on clinical grounds as acquired

Address correspondence to Mark Keating, Department of Human Genetics, Building 533, Room 2100, University of Utah, Salt Lake City, UT 84112.

Received for publication 19 January 1993 and in revised form 15 March 1993.

1. Abbreviations used in this paper: $\mathrm{H}$ ras-1, Harvey ras- 1 ; LOD, logarithm of odds; LQT, long QT; TH, tyrosine hydroxylase.

J. Clin. Invest.

(C) The American Society for Clinical Investigation, Inc

0021-9738/93/08/0799/05 \$2.00

Volume 92, August 1993, 799-803 or inherited. The most common acquired form of LQT is druginduced (1), but metabolic, neurologic, and cardiac abnormalities can also cause this disorder.

LQT can be caused by the inheritance of a single gene (2). Two inherited forms of LQT are clearly defined on phenotypic and genetic grounds. One is inherited as an autosomal recessive trait and is associated with congenital neural deafness ( 3 ). This form of LQT, often referred to as the Jervell Lange-Nielsen syndrome, is rare. The second, more common, heritable form of LQT is an autosomal dominant trait and is often called the Romano-Ward syndrome $(4,5)$. Individuals with autosomal dominant LQT have normal hearing and no other obvious phenotypic abnormalities.

Presymptomatic diagnosis of inherited LQT has been based on family history and electrocardiographic findings. As the QT interval is affected by age, sex, autonomic tone, and heart rate, and varies widely among both affected and unaffected individuals, the diagnosis of LQT in an asymptomatic individual may be difficult (6). This is a matter of considerable importance as treatment for LQT exists.

To improve our understanding of the mechanisms underlying LQT and to facilitate presymptomatic diagnosis of this disorder, we have begun to study families with autosomal dominant LQT. In 1991, we reported tight linkage between the LQT phenotype and the Harvey ras-1 ( $\mathrm{H}$ ras-1) gene in several families of northern European descent $(2,7)$. These data confirmed the autosomal dominant inheritance of an LQT gene in seven families and mapped that gene to the short arm of chromosome $11(11 \mathrm{p} 15.5)$. The discovery of linked genetic markers also made genetic testing for LQT feasible for some families. To determine if $\mathrm{H}$ ras- 1 was useful for genetic testing in additional patients, we examined other families with autosomal dominant LQT. In this report, we characterized two new LQT families, one of Polish descent and another of Italian descent, and showed that the gene for LQT in these families was not linked to $\mathrm{H}$ ras- 1 .

\section{Methods}

Phenotypic determination. Kindreds 1977 and 1756 were not previously described. Informed consent was obtained from all study participants or their guardians, in accordance with standards established by local institutional review boards. To determine if family members and spouses had evidence of LQT, we obtained historical data and electrocardiograms from each individual before starting drug treatment. One individual (II-1, K1756) was evaluated while being treated with a beta blocker for hypertension. We evaluated the presence of syncope, the number of syncopal episodes, the age at onset of symptoms, and the 


\section{A $\mathrm{K} 1756$}

।

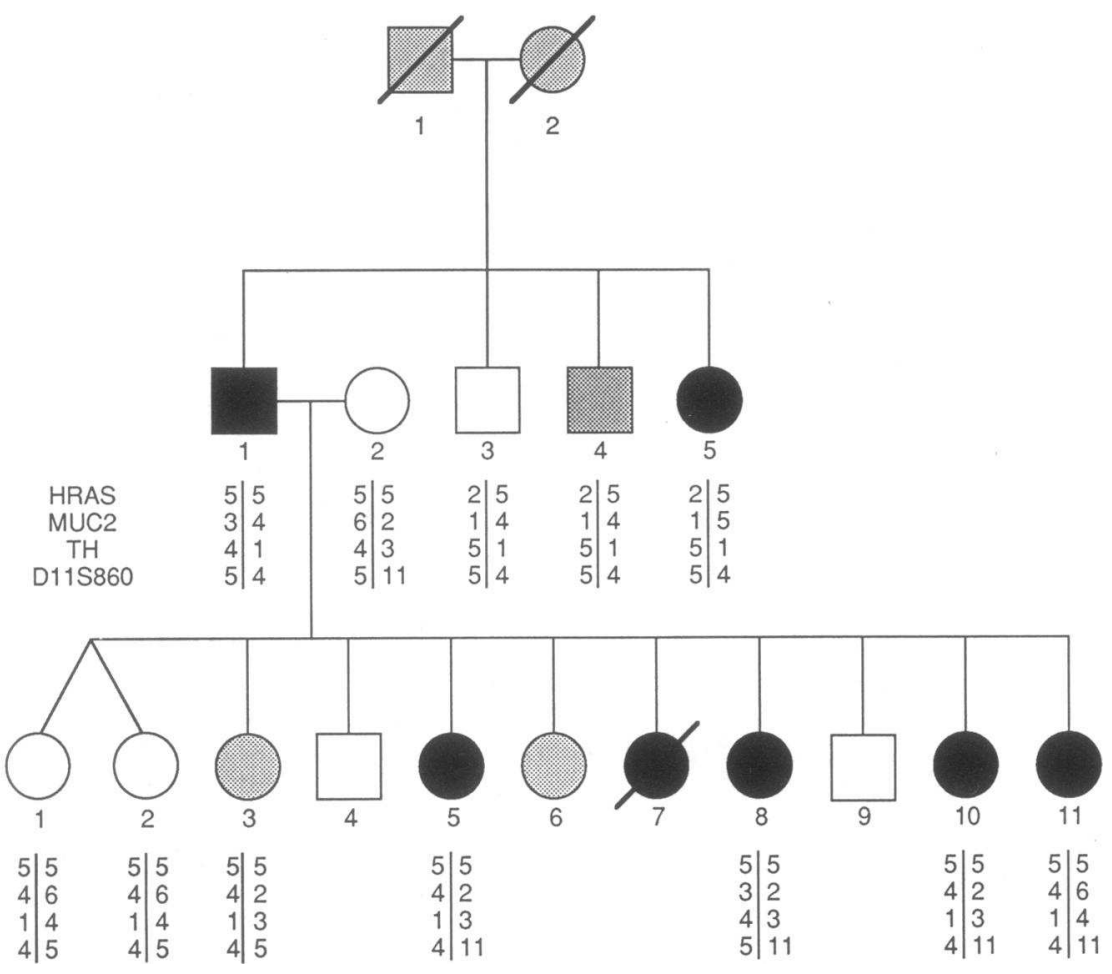

II

III

\section{B K1977}

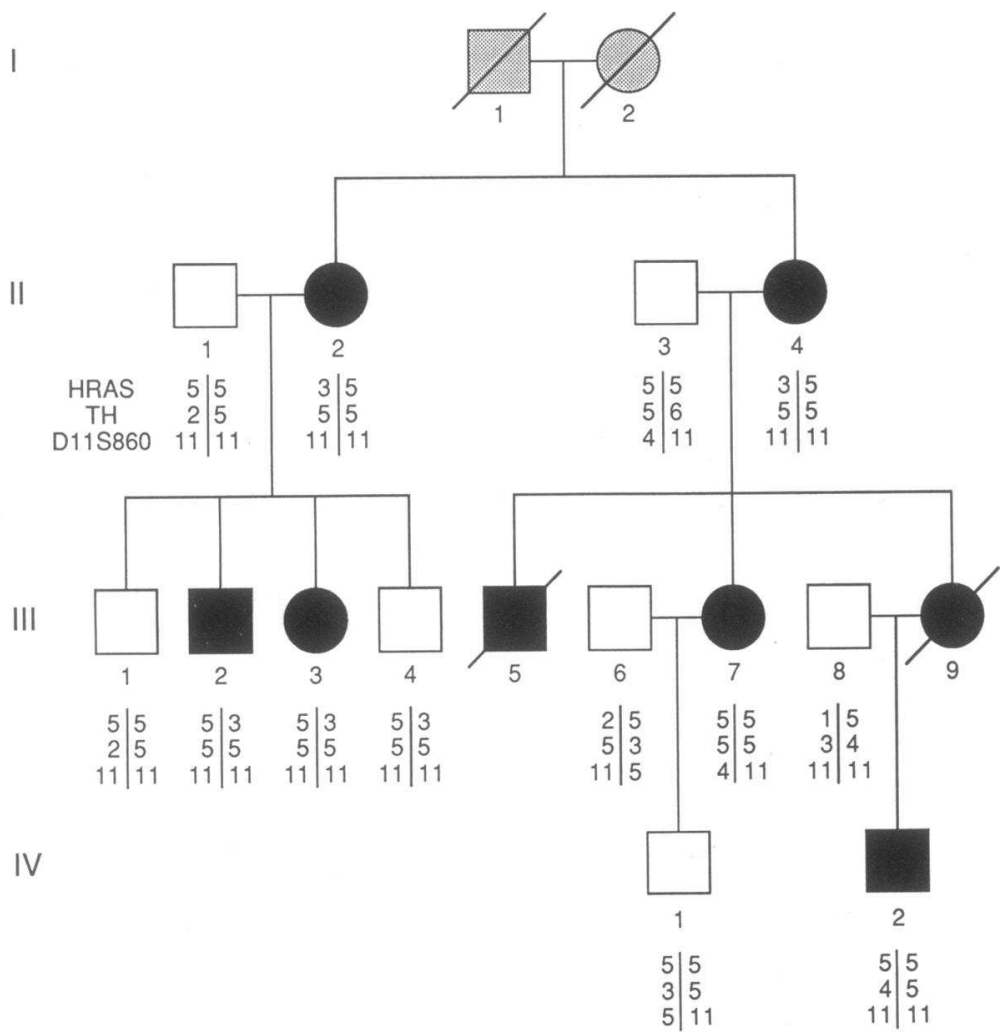

Figure 1. LQT pedigrees for K1756 $(A)$ and $\mathrm{K} 1977(B)$ showing haplotypes for $\mathrm{H}$ ras-1, MUC2, TH, and D11S860. Affected individuals are represented by filled circles (females) or squares (males). Unaffected individuals are shown as empty circles or squares and individuals with an uncertain phenotype are stippled. DNA samples for individuals III-4, III-6, and III-9 were unavailable for genotypic analysis. The pedigrees have been altered to protect confidentiality. Informed consent was obtained for each family member before inclusion in the study. Haplotype recombinants described in the text occur in individuals III-3 and III- 11 . 
Table I. Clinical Symptoms of Affected Individuals in K1756 and K1977

\begin{tabular}{|c|c|c|c|c|c|}
\hline Individual & Sex & $\mathrm{QT}_{\mathrm{c}}$ & $\begin{array}{l}\text { Age of } \\
\text { onset of } \\
\text { syncope }\end{array}$ & $\begin{array}{c}\text { Age of } \\
\text { sudden } \\
\text { death }\end{array}$ & Precipitating factors \\
\hline & & & $y r$ & $y r$ & \\
\hline A II 1 & Male & 0.51 & 50 & - & Awakening \\
\hline A II 5 & Female & 0.47 & - & - & - \\
\hline A III 5 & Female & 0.56 & - & - & - \\
\hline A III 7 & Female & NA & 13 & 15 & $\begin{array}{l}\text { Died upon } \\
\text { awakening }\end{array}$ \\
\hline A III 8 & Female & 0.59 & 16 & - & Awakening \\
\hline A III 10 & Female & 0.48 & - & - & - \\
\hline A III 11 & Female & 0.47 & - & - & - \\
\hline B II 2 & Female & 0.49 & 22 & - & Standing \\
\hline B II 4 & Female & 0.47 & - & - & - \\
\hline B III 2 & Male & 0.47 & - & - & - \\
\hline B III 3 & Female & 0.48 & - & - & - \\
\hline B III 5 & Male & NA & NA & 20 & $\begin{array}{c}\text { Died while } \\
\text { sleeping }\end{array}$ \\
\hline B III 7 & Female & 0.49 & 12 & - & Resting \\
\hline B III 9 & Female & 0.46 & 一 & 31 & $\begin{array}{c}\text { Died while } \\
\text { sleeping }\end{array}$ \\
\hline B IV 2 & Male & 0.53 & - & - & - \\
\hline
\end{tabular}

$\mathrm{QT}_{\mathrm{c}}$, corrected QT interval, defined in references 2, 5, 6, and 7 cited in Methods.

occurrence of sudden death. Symptoms such as palpitations and lightheadedness were not included in the study.

To determine the phenotype of each family member and avoid misclassifications, we took a conservative approach to phenotypic assignment. Each individual was assigned an impression score based on the presence and extent of symptoms and QTc prolongation. Impression scores were used to classify family members as affected, unaffected, or uncertain. All phenotypic data were interpreted without knowledge of genotype. Phenotypic characterization was completed using the same criteria as in our previous linkage studies $(2,7,8)$.

Typing of RFLP markers. Two DNA markers, known to define polymorphisms on chromosome $11 \mathrm{p} 15.5$ were used: pTBB-2 at the $\mathrm{H}$ ras-1 locus (9) and pSMUC41 at the MUC2 locus (10). Genotyping of RFLP markers was performed as previously described (7).

Typing of PCR-based polymorphic markers. Typing of PCR markers was performed as described by Weber and May (11) with the following modifications. PCR was carried out on $200 \mathrm{ng}$ of DNA in a final vol of $25 \mu$ l using a DNA thermocycler (Perkin-Elmer Cetus Instruments, Norwalk, CT). Amplification conditions were $94^{\circ} \mathrm{C} / 10$ min followed by 30 cycles of $60^{\circ} \mathrm{C} / 60 \mathrm{~s}, 72^{\circ} \mathrm{C} / 60 \mathrm{~s}$, and $94^{\circ} \mathrm{C} / 60 \mathrm{~s} .25$ $\mu \mathrm{l}$ of loading buffer was added to each reaction, samples denatured for $10 \mathrm{~min}$ at $94^{\circ} \mathrm{C}$ and held on ice. A portion $(2.5 \mu \mathrm{l})$ of each sample was separated by electrophoresis on $6 \%$ denaturing polyacrylamide gels which were dried and exposed to $\mathrm{x}$-ray film overnight at $-70^{\circ} \mathrm{C}$. The following simple sequence repeat markers were used in this study: D11S860 (12) and tyrosine hydroxylase (TH) (13).

Linkage analysis. To avoid bias all polymorphisms were scored without knowledge of an individual's phenotypic status. The LINKAGE software package was used to perform both pairwise and multipoint linkage analysis. Penetrance was estimated at 0.90 , based on previous estimates (2). We assumed a disease gene frequency of 0.001 and that female and male recombination frequencies were equal. Marker order and distance between markers was determined from published genetic maps and our unpublished data (14).
Table II. Pairwise Lod Scores for K1756 and K1977

\begin{tabular}{|c|c|c|c|c|c|c|c|}
\hline & \multicolumn{7}{|c|}{ Recombination fraction $(\theta)$} \\
\hline & 0.00 & 0.001 & 0.05 & 0.1 & 0.2 & 0.3 & 0.4 \\
\hline \multicolumn{8}{|c|}{$H R A S$} \\
\hline \multicolumn{8}{|l|}{ Kindred } \\
\hline K1756 & -0.31 & -0.30 & -0.23 & -0.17 & -0.09 & -0.04 & -0.01 \\
\hline K1977 & -2.72 & -2.64 & -1.34 & -0.87 & -0.40 & -0.17 & -0.05 \\
\hline \multicolumn{8}{|c|}{$M U C 2$} \\
\hline K1756 & -6.67 & -5.54 & -2.28 & -1.49 & -0.68 & -0.27 & -0.06 \\
\hline \multicolumn{8}{|c|}{$T H$} \\
\hline K1756 & -3.65 & -3.37 & -1.70 & -1.18 & -0.57 & -0.23 & -0.06 \\
\hline K1977 & +0.35 & +0.35 & +0.30 & +0.26 & +0.17 & +0.10 & +0.04 \\
\hline \multicolumn{8}{|c|}{$D 11 S 860$} \\
\hline K1756 & -2.90 & -2.83 & -1.63 & -1.12 & -0.54 & -0.22 & -0.05 \\
\hline K1977 & -0.44 & -0.44 & -0.32 & -0.24 & -0.14 & -0.08 & -0.04 \\
\hline
\end{tabular}

LOD scores (pairwise) between LQT and polymorphic markers used in this study. LOD scores were calculated assuming a penetrance value of 0.90 and the frequency of LQT was 0.001 as in our previous studies. When penetrance was varied from 1.0 to $0.6 \mathrm{LOD}$ scores ranged from -9.42 to $-5.08(\Theta=0.001)$ at MUC2 in K1756 and from -4.68 to $-2.01(\Theta=0.001)$ at $\mathrm{H}$ ras-1 in K1977. Male and female recombination rates were assumed to be equal. Allele frequencies for D1 1S860 were obtained from published reports (12). Allele frequencies for pTBB2 were calculated from 196 independent chromosomes, TH allele frequencies were calculated from 200 chromosomes and pSMUC41 from 78 chromosomes.

\section{Results}

Phenotypic analyses. We studied two multigenerational families with autosomal dominant LQT (Fig. 1). Kindred 1756 was of Italian descent and included 16 family members. Three individuals had a history of syncope; in all cases, syncope occurred immediately after awakening (Table I). One member of this family, individual III-7, died suddenly upon awakening at age 15. This individual also had a history of recurrent syncope upon awakening. Electrocardiogram data were not available for this patient. Autopsy results were unremarkable.

Kindred 1977 was of Polish descent and included 15 family members. Two members of this family had syncopal episodes and two died suddenly (Table I). Members of this kindred experienced syncope while at rest and both deaths occurred during sleep, one at age 20 (individual III-5) and the second at age 31 (individual III-9).

All living members of kindreds 1756 and 1977, with the exception of individual II- 1 in K1977, were evaluated for symptoms and signs of LQT. We examined a total of 15 individuals from K1756 and thirteen individuals from K1977 (Table I). As a result, six living members from K1756 were classified as affected, five as unaffected and three as uncertain (Fig. 1). In K1977, six individuals were classified as affected and three members as unaffected (Fig. 1). 

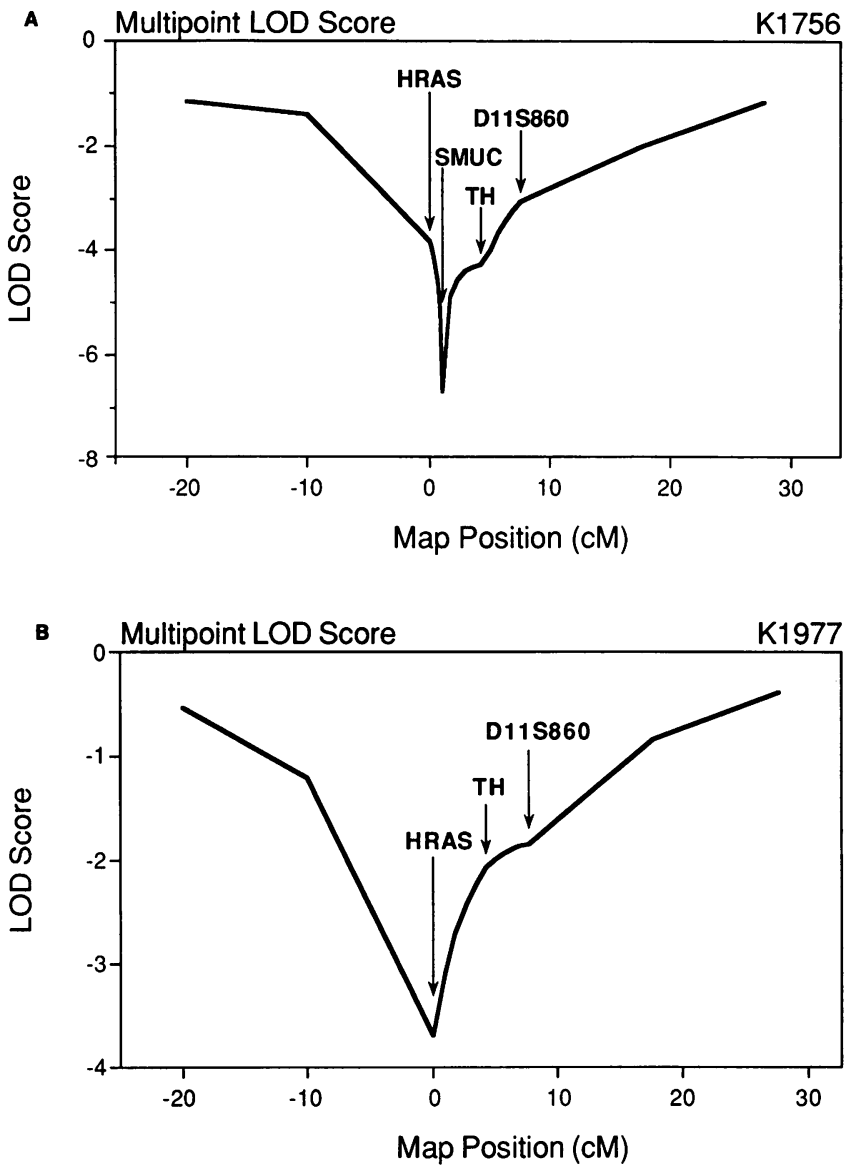

Figure 2. Multipoint linkage analysis of LQT and chromosome 11 p15.5 markers for $\mathrm{K} 1756(A)$ and $\mathrm{K} 1977(B)$. The location map shows composite LOD scores for LQT at different positions in a fixed marker map. $\mathrm{H}$ ras- 1 is arbitrarily placed at 0 centiMorgans. Marker order and distances were based on published maps of chromosome $11 \mathrm{p} 15(14)$.

Linkage analyses. To determine if the gene causing LQT in these families was located on chromosome $11 \mathrm{p} 15.5$, we performed linkage analyses using highly polymorphic markers at the $\mathrm{H}$ ras-1 locus. We obtained a significant negative logarithm of odds (LOD) score (LOD score of -2 or lower) of -2.64 for kindred 1977 at a recombination fraction $(\theta)$ of 0.001 (Table II). These data suggested that the LQT phenotype was not linked to the $\mathrm{H}$ ras-1 locus in this kindred. Markers at $\mathrm{H}$ ras- 1 were relatively uninformative for linkage in kindred 1756 (LOD score of -0.30 at $\theta=0.001$ ). To improve informativeness in this kindred, we used a second DNA marker very near $\mathrm{H}$ ras-1, the MUC2 locus (SMUC 41) and obtained a LOD score of -5.54 at $\theta=0.001$ (Table II). As $\mathrm{H}$ ras- 1 and SMUC are tightly linked (10), these data suggest that the gene responsible for LQT in both kindreds are not linked to the $\mathrm{H}$ ras-1 locus.

Additional markers and multipoint analyses. The precise location of the LQT gene within $11 \mathrm{p} 15.5$ is not known. It is possible, therefore, that recombination events between the LQT locus and DNA markers near $\mathrm{H}$ ras-1 might account for our failure to identify linkage in these families. To exclude this possibility, we performed linkage analyses with polymorphic markers from different regions of $11 \mathrm{p} 15.5$. Pairwise analysis in kindred 1756 produced LOD scores of $-3.37(\theta=0.001)$ for TH and -2.83 at $(\theta=0.001)$ for D1 1 S860 (Table II). Pairwise LOD scores for kindred 1977 were $0.35(\theta=0.001)$ for $\mathrm{TH}$ and $-0.44(\theta=0.001)$ for D11S860. Haplotype analyses showed two marker-marker recombination events, both occurring in K1756 between the TH and D11S860 markers. As shown in Fig. 1 the first event occurred between the unaffected parent II-2 and affected child III-3. The second event occurred between individual II-2 and affected child III- 11 . As both of these recombination events involve transmission of alleles from the unaffected, married-in parent, there is no significant impact on the linkage analysis. Inspection of Fig. 1 demonstrated the presence of several obligate recombinants within each family. Multipoint analyses excluded, at the -2 LOD level, greater than 6 centiMorgans on either side of $\mathrm{H}$ ras-1 for both kindreds (Fig. $2, A$ and $B$ ). As the one LOD confidence interval for previous LQT families which are linked to $\mathrm{H}$ ras- 1 is $\sim 3$ centiMorgans (7), these data indicate that the gene that causes LQT in kindreds 1756 and 1977 is not linked to $\mathrm{H}$ ras-1.

\section{Discussion}

We conclude that the gene that causes LQT in the two families described here is not linked to the $\mathrm{H}$ ras-1 gene on chromosome $11 \mathrm{p} 15.5$. Since our initial discovery of linkage in 1991, several groups have suggested the existence of locus heterogeneity for autosomal dominant LQT. In the fall of 1991, Towbin reported preliminary data suggesting that the LQT phenotype in a large family with autosomal dominant LQT was not linked to $H$ ras-1 (15). In the spring of 1992, Benhorin and his colleagues described a large Israeli family with an absence of linkage between LQT and $\mathrm{H}$ ras-1 (16). Jeffery et al. reported that two siblings with autosomal recessive LQT and congenital neural deafness (Jervell Lange-Nielsen syndrome) had distinct $\mathrm{H}$ ras-1 genotypes (17). Although this kindred was much too small for statistical analyses, these data suggest that autosomal dominant and autosomal recessive LQT are mechanistically distinct. In this study we characterized two families with autosomal dominant LQT using consistent and accurate phenotypic criteria $(2,7,8)$ and multiple markers from chromosome $11 \mathrm{p} 15.5$. Our study demonstrates statistical evidence of locus heterogeneity for autosomal dominant LQT, suggesting that at least two different mechanisms for this disorder exist.

It is not yet clear what percentage of familial LQT will be caused by mutations in a gene on chromosome $11 \mathrm{p} 15.5$. We have examined 13 families. Of those, LQT is clearly linked to Harvey ras-1 (or other chromosome 11 markers) in 7 and clearly unlinked in 2 . The remaining families were too small for significant statistical evaluation. Further work will be required on additional families before the relative importance of the $11 \mathrm{p} 15.5$ gene will be apparent.

As in previous studies, we used conservative criteria for phenotypic classification of LQT family members $(2,7,8)$. Individuals were assigned an impression score based on the presence and extent of symptoms and electrocardiographic signs of LQT. Recently we demonstrated that many LQT gene carriers are asymptomatic and can have a wide range of resting QTc values; the lowest QTc for a LQT gene carrier in that study was $0.41 \mathrm{~s}$ whereas the highest QTc for a noncarrier was $0.47 \mathrm{~s}$ 
(8). Misclassification of a few family members could lead to false conclusions about the presence or absence of linkage in a family, so continued conservative phenotypic classification is warranted.

The phenotype of affected members of the families described here appears different from that of previously studied families. The incidence of sudden death was $\sim 11 \%$ for kindred 1756 and $18 \%$ for kindred 1977 . By contrast, the incidence of sudden death in three large chromosome 11-linked families was lower at $\sim 4 \%$. The factors that precipitated arrhythmias in these families also differed from families linked to 11p15.5. In kindred 1756 symptoms occurred upon awakening and in kindred 1977 symptoms occurred at rest. Two individuals in this family died during sleep. By contrast, in chromosome 11-linked families arrhythmias were frequently precipitated by exercise or anxiety $(50 \%)$. In future studies it will be of interest to determine the phenotypic consequences of different LQT mutations.

The identification of locus heterogeneity for autosomal dominant LQT will complicate genetic testing for this disorder. Genetic testing in a family is feasible only after LQT has been linked to chromosome 11 markers in that family. It will be difficult, therefore, to use genetic diagnosis in small families.

The mechanism of QT prolongation in LQT is unknown but may involve prolonged action potential duration in individual cardiac myocytes and dispersion of cardiac repolarization, or afterdepolarizations which contribute to the expression of repolarization potentials on the surface ECG. In theory, anything that affects myocellular depolarization and repolarization could cause LQT. As the autonomic nervous system is an important mediator of cardiac repolarization, it has also been hypothesized that genes involved in the development and regulation of autonomic innervation could be involved in this disorder $(18,19,20,21)$. Given the multiple possible mechanisms that could cause LQT, it should not be surprising that two or more different genetic mechanisms may account for this disorder.

\section{Acknowledgments}

We thank J. Robinson, A. Ewart, V. Turner, M. Woodward, P. Cartwright, and R. White for their help and advice.

This work was supported in part by National Institutes of Health grants RO1HL-4807 and RO1HL-33843, an American Heart Association Established Investigator Award, Public Health Services research grant No. MO1-RR00064 from the National Center for Research Re- sources, a Syntex Scholars Award, the Technology Access Section of the Utah Genome Center, and the LDS Hospital Deseret Foundation.

\section{References}

1. Zipes, D. P. 1987. Proarrhythmic effects of antiarrhythmic drugs. Am. J. Cardiol. 59:26E-31E.

2. Keating, M. T., C. Dunn, D. Atkinson, K. Timothy, G. M. Vincent, and M. Leppert. 1991. Linkage of a cardiac arrhythmia, the long QT syndrome, and the Harvey ras-1 gene. Science (Wash. DC). 252:704-706.

3. Jervell, A., and F. Lange-Nielsen. 1957. Congenital deaf mutism, functional heart disease with prolongation of the QT interval, and sudden death. $\mathrm{Am}$. Heart J. 54:59-78.

4. Ward, O. C. 1964. A new familial cardiac syndrome in children. J. Ir. Med. Assoc. 54:103-106.

5. Romano, C. 1965. Congenital cardiac arrhythmia. Lancet. i:658-659.

6. Vincent, G. M., D. Jaiswal, and K. Timothy. 1991. The effect of exercise on heart rate, QT, QTc and QT/QS2 in the Romano-Ward inherited long QT syndrome. Am. J. Cardiol. 68:498-503.

7. Keating, M. T., D. Atkinson, C. Dunn, K. Timothy, G. M. Vincent, and M. Leppert. 1991. Linkage of the long QT syndrome to the Harvey ras-1 locus on chromosome 11. Am. J. Hum. Genet. 49:1335-1339.

8. Vincent, G. M., K. W. Timothy, M. Leppert, and M. Keating. 1992. The spectrum of symptoms and QT intervals in carriers of the gene for the long QT syndrome. $N$. Engl. J. Med. 327:846-852.

9. Goldfarb, M., K. Shimizu, M. Perucho, and M. Wigler. 1982. Isolation and preliminary characterization of a human transforming gene from T24 bladder carcinoma cells. Nature (Lond.). 296:404-409.

10. Griffiths, B., D. J. Matthews, L. West, J. Attwood, S. Povey, D. M. Swallow, J. R. Gum, and Y. S. Kim. 1990. Assignment of the polymorphic intestinal mucin gene (MUC2) to chromosome 11p15. Ann. Hum. Genet. 54:277-285.

11. Weber, J. L., and P. E. May. 1989. Abundant class of human DNA polymorphisms which can be typed using the polymerase chain reaction. Am. J. Hum. Genet. 44:388-396.

12. McNoe, L. A., M. R. Eccles, and A. E. Reeve. 1991. Dinucleotide repeat polymorphism at the D11S860 locus. Nucleic Acids. Res. 20:1161.

13. Polymeropoulos, M. H., H. Xiao, D. S. Rath, and C. R. Merril. 1991. Tetranucleotide repeat polymorphism at the human tyrosine hydroxylase gene (TH). Nucleic Acids. Res. 19:3753.

14. Kramer, P., W. Becker, P. Heutink, M. James, C. Julier, M. Lathrop, J. A Luty, Z. Wang, J. L. Weber, P. Wilkie, and M. Litt. 1992. A comprehensive genetic linkage map of the Human Genome/NIH/CEPH collaborative Mapping Group. Science (Wash. DC). 258:67-86.

15. Towbin, J. A., L. Pagotto, B. Sju, J. Robinson, A. Moss, E. R. B. McCabe, and J. F. Heitmancik. 1992. Romano-Ward long QT syndrome (RWLQTS): evidence of genetic heterogeneity. Pediatr. Res. 31:125A. (Abstr.)

16. Kerem, B., J. Benhorin, Y. M. Kalman, A. Medina, T. D. Dyer, J. Blangero, and J. W. MacCluer. 1992. Evidence for genetic heterogeneity in the long QT syndrome. Am. J. Hum. Genet. 51:192A. (Abstr.)

17. Jeffery, S., R. Jamieson, M. A. Patton, and J. Till. 1992. Long QT and Harvey-ras. Letter to the Editor. Lancet. 339:255.

18. Yanowitz, F., J. Preston, and A. Abildskov. 1966. Functional distribution of right and left stellate inervation to the ventricals. Circ. Res. 18:416-428.

19. Moss, A. J., and J. McDonald. 1971. Unilateral cervical ganglionectomy for the treatment of the long QT syndrome. N. Engl. J. Med. 285:903-904.

20. Schwartz, P., and E. Locati. 1985. The idiopathic long QT syndrome: pathogenic mechanisms and therapy. Eur. Heart J. 6:103-114.

21. Schwartz, P. J., E. Locati, S. G. Priori, and A. Zaza. 1990. The long QT syndrome. In Cardiac Electrophysiology from Cell to Bedside. D. P. Zipes and J. Jalife, editors. W.B. Saunders Co., Philadelphia. 589-605. 